\title{
The Sensitivity of Wind Forecasts with a Mesoscale Meteorological Model at the Centro de Lançamento de Alcântara
}

\author{
Elizabeth Diane de Jesus Reuter1,2, Gilberto Fisch³, Cleber Souza Correa ${ }^{4}$
}

\begin{abstract}
The sensitivity of the planetary boundary layer (PBL) parameterizations is investigated using the hybrid Fifth Generation Penn State University/National Center for Atmospheric Research (NCAR) Mesoscale Model (MM5) and its results were compared with observations from two field campaigns held during the dry and wet seasons at the Centro de Lançamento de Alcântara (CLA). The comparisons were made using the integrated zonal and meridional components of observed and forecasted winds. Initially, three boundary layer parameterizations, in addition to the current parameterization, were selected for evaluation: Blackadar (BLK), Medium Range Forecast (MRF), Janjic (ETA) and Burk-Thompson (BT). The MRF and BLK schemes produced better results than the ETA and BT schemes. Nevertheless, MRF and BLK underestimate the zonal and meridional wind components by around 16\% in the rainy season and overestimate them by on average $18 \%$ in the dry season.
\end{abstract}

KEYWORDS: Centro de Lançamento de Alcântara, MM5, Boundary layer parameterizations.

\section{INTRODUCTION}

Nowadays, in the field of Aerospace Meteorology, atmospheric modeling and numerical simulations are necessarily present in the operational planning and logistics of space vehicle launches, with the goals of guaranteeing higher security in the activities on the surface and in flight and thus contributing to the success of the launches. The Aerospace Meteorology is the application of atmospheric science towards the design, development, and operation of aerospace vehicles. At the Centro de Lançamento de Alcântara (CLA), it supports the observation missions and analysis of climate elements at the surface and altitude, as well as produces the weather forecast.

An aerospace vehicle's response to atmospheric disturbances, especially wind, must be carefully evaluated to ensure that the design will meet its operational requirements (Johnson, 2008).

A large number of different Numerical Weather Prediction models have been utilized in the operational sectors of Meteorology as a work tool. However, the limitations of each of them mean that, for each particular problem, it is necessary to develop or modify a code according to the specific desired requirements. In the case of rocket launches at the CLA, the search for a model capable of predicting the shear and wind profile with antecedence of hours in a large area of ocean-continent transition is very important given the operational necessity of understanding the winds for the determination of the vehicle trajectory and for studies of dispersion of the gases liberated by rocket combustion processes at the surface level at the launch pad.

1.Instituto Nacional dePesquisasEspaciais-Centro dePrevisãode TempoeEstudosClimáticos-SãoJosédosCampos/SP-Brazil. 2.Secretaria da AviaçãoCivil-Empresa Brasileira de Infraestrutura Aeroportuária - Guarulhos/SP - Brazil. 3.Departamento de Ciência e Tecnologia Aeroespacial - Instituto de Aeronáutica e Espaço - Divisão de Ciências Atmosféricas - São José dos Campos/SP - Brazil. 4. Departamento de Controle do Espaço Aéreo - Instituto de Controle de Tráfego Aéreo - Rio de Janeiro/RJ - Brazil. Author for correspondence: Gilberto Fisch | Instituto de Aeronáutica e Espaço - Divisão de Ciências Atmosféricas | Praça Marechal Eduardo Gomes, 50 - Vila das Acácias | CEP: 12.228-901 - São José dos Campos/SP - Brazil | Email: gfisch@iae.cta.br

Received: 07/07/2014| Accepted: 03/22/2015 
Although each physical parameterization package in a mesoscale model plays an important role in atmospheric simulations, the parameterizations of the planetary boundary layer (PBL) are formulations more simple than the complex physical processes that occur in the nearest layers of the Earth's surface. For better understanding, some definitions are important such as: mesoscale is the scale of meteorological phenomena that ranges in size from a few $\mathrm{km}$ to about $100 \mathrm{~km}$. It includes local winds, thunderstorms, and tornadoes. PBL is the bottom layer of the troposphere that is in contact with the surface of the Earth. It is often turbulent and is capped by a statically stable layer or temperature inversion of air. Surface boundary layer $(\mathrm{SBL})$ is the layer of air of order tens of meters thick adjacent to the ground where mechanical (shear) generation of turbulence exceeds buoyant generation or consumption.

The PBL parameterizations are mathematical formulations simpler than the complex physicals processes that occur in the layers closest to the Earth's surface. The principal process is turbulence, which is responsible for the vertical distribution of the properties related to heat surface fluxes, moisture and momentum within the PBL.

The realistic importance, in other words, the faithful representation of the existing processes in the PBL and SBL in meteorological models, is out of question, principally in mesoscale models. It should be taken into consideration because the majority of these parameterizations were developed based on measurements and studies conducted in Northern Hemisphere mid-latitude locations, principally in the United States and Europe. Thus, it is necessary to study the influence of these schemes on the simulation of meteorological variables in other regions, particularly in the equatorial region. There are relatively few validation studies of numerical weather models for the equatorial region: for instance, Oyama (2004), in a preliminary study, evaluated the sensitivity of the MM5 model to the deep convective parameterizations on reduced grids; Oyama and Giarolla (2006) simulated squall lines on the northern coast of Brazil also using the MM5 model. These simulations were performed in order to verify the ability of the model to represent the life cycle of squall lines (LI) initiated in the northern coast of Brazil. Squall line is a line of active thunderstorms, either continuous or with breaks, including contiguous precipitation areas resulting from the existence of the thunderstorms. The MM5 satisfactorily represented the life cycle of LI and, as a consequence, the weather; Pereira Neto and Oyama (2011) proposed adjustments in the Kain-Fritsch
(KF2) deep convective parameterization scheme with the goal of improving precipitation prediction at the CLA. With the adjustments, a marked improvement in the representation of the total precipitation and of the monthly fraction of rainy days was found.

The spatial pattern of errors in the field, however, has not undergone many changes over the continent and, in general, rainfall is best represented over land than over ocean. Also using the MM5 regional model, Carvalho (2011) tested the sensitivity of simulated precipitation to different schemes of explicit convection, the activation of shallow convection (Grell, 1993) and adjustments in the scheme of deep convection KF2 scheme. Adjustments in KF2 comprehended changes in minimum depth of cloud required to activate the convection in the parameters "trigger" function and convective scales of advective and convective weather. The modeling study showed that the use of explicit convection "warm rain" and shallow convection schemes of Grell along with the "in line" in KF2 substantially reduced the overestimation of precipitation found in the simulations for the operating region of the Intertropical Convergence Zone - the axis, or a portion thereof, of the broad trade-wind current of the Tropics (ITCZ). All of these studies contributed to a better understanding of how to utilize atmospheric mesoscale modeling, in particular, the MM5 model, at the CLA region in order to support the launchings. However, they did not address the ability of the mesoscale model to forecast winds. The rainfall and the winds, both at surface and upper air, are the two key-parameters for the launchings of Brazilian rockets at CLA.

So, in order to use a numerical model to forecast the winds at the CLA, this study addressed the question of its evaluation using four different PBL parameterizations, to be described in section Description of the Modified MM5 Model, against data sets collected by radiosonde winds from the surface up to 5,000 m during wet and dry periods.

\section{DATA}

The experimental data collection was made at the CLA. The CLA is located on the coast of the state of Maranhão, with geographic coordinates of latitude $2^{\circ} 19^{\prime} \mathrm{S}$, longitude $44^{\circ} 22^{\prime} \mathrm{W}$ and an altitude of $49 \mathrm{~m}$, distant $30 \mathrm{~km}$ from the city of São Luís do Maranhão. Figure 1 shows a panoramic view of the CLA and the grid/domain utilized in the simulations with the MM5 model. 


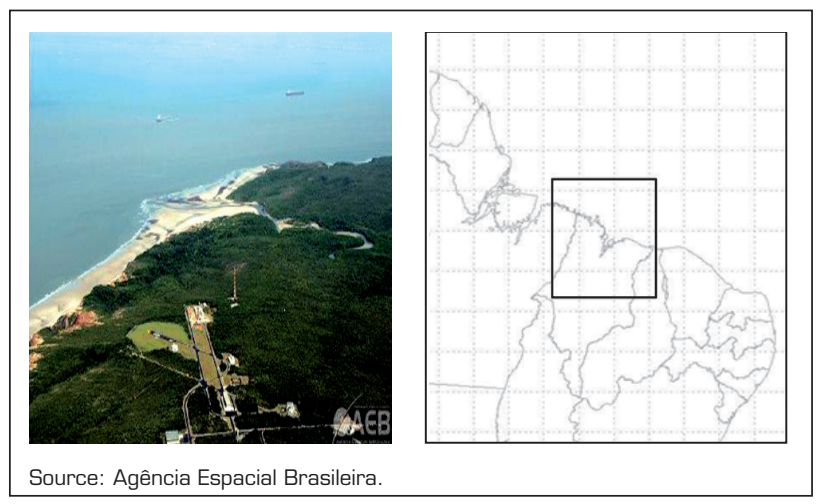

Figure 1. Aerial view of the CLA and grids with horizontal resolutions of $18 \mathrm{~km}$ (larger domain) and $6 \mathrm{~km}$ (smaller domain).

The data were obtained from two field campaigns: Operation Murici 2008, during the dry season of 2008, and GPM 2010, wet season of 2010, and consist of systematic radiosounding launched at 00, 06, 12 and 18 UTC, during the periods from September 16-26, 2008, characterizing the dry season, to from March 19-25, 2010, characterizing the wet period. Meteorological parameters such as pressure, temperature and humidity were measured by the radiosonde in situ sensors while the direction and wind speed were determined by the GPS satellite navigation. The radiosonde soundings were performed using equipment model Vaisala OY (DigiCORA) using the sondes RS80-15G and RS92-SVP in experiments in 2008 and 2010, respectively.

\section{DESCRIPTION OF THE MODIFIED MM5 MODEL}

In this study, the hybrid Fifth Generation Penn State University/National Center for Atmospheric Research (NCAR) Mesoscale Model (MM5) (Grell et al., 1994; Dudhia et al., 2003) was utilized. The model is for numerical simulation of the atmosphere and was developed in the late 1970s by Penn State University, in conjunction with the National Center for Atmospheric Research (PSU/NCAR). In Brazil, the Laboratório de Prognósticos em Mesoescala (LPM) of the Departamento de Meteorologia of the Universidade Federal do Rio de Janeiro (UFRJ) provides predictions for the state of Rio de Janeiro with $20 \mathrm{~km}$ resolution. The Instituto de Controle do Tráfico Aéreo (ICEA), on the other hand, in partnership with the Centro Nacional de Meteorologia Aeronáutica (CNMA), both subordinated to the Departamento de Controle do Espaço Aéreo (DECEA) and the IAE of Departamento de Ciência e Tecnologia Aeroespacial (DCTA), uses the MM5 model with objectives of research and operational numerical modeling for aeronautical and space vehicle. The numerical simulation tests were conducted in the ICEA/DECEA research facility, which is located within the DCTA.

As the model was developed in order to simulate or predict atmospheric circulation, it is supported by pre- and postprocessing programs. The MM5 model is a limited area model, which needs lateral boundary conditions to represent the real state of the atmosphere neighboring the simulation domain through the time of integration of the dynamic equations. These boundary conditions are obtained through a global scale atmospheric model, for example, the Global Forecast System (GFS), obtained from the address: http://www.ncdc.noaa.gov/data-access/model-data/ model-datasets/global-forcast-system-gfs.

The modeling system consists of a set of components necessary to run the model: the Pre-processing System (WPS), the pre-processing package used in the Weather Research and Forecasting (WRF) Model, which horizontally interpolates the meteorological variables of geopotential height, wind, temperature and mixing ratio in each isobaric level, temperature and pressure on the surface and temperature and humidity of the soil layers; in this way, the version used MM5 can be considered hybrid format GRIB2. In this version of MM5, the REGRID package horizontally interpolates the analyzes and forecasts, the INTERPF vertically interpolates the pressure to sigma coordinates and also generates the initial and boundary conditions; in MM5, there are the parameter definitions, implementation of the model and periods of integration and assimilation of data and MM5toGrADS is done post-processing, which generates converted output to GrADS format. In this way, the version of MM5 used can be considered hybrid format GRIB2. Figure 2 depicted the flow chart of MM5.

This study considers the following parameterizations: Blackadar (BLK), described by Zhang and Anthes (1982), BurkThompson (BT; Burk and Thompson, 1989), ETA (Mellor and Yamada (1974); Janjic (1994) and Hong-Pan (Medium Range Forecast - MRF); Hong and Pan, 1996) PBL schemes available in the MM5 model, in agreement with Table 1.

A high-resolution, one-dimensional, moist PBL model is developed following Blackadar (1976) and verified using the 10 April 1979 SESAME data set (Zhang and Anthes, 1982). The model consists of two modules to predict the time-dependent behavior of the PBL under various surface characteristics. Under stable conditions, turbulent fluxes are related to a local Richardson number. In contrast, unstable conditions commonly said to free 
convection, the heat exchange, humidity and momentum occur through mixing between elements originating at the surface and the environmental air PBL. The stable regime, also known as nighttime, and the unstable regime are treated differently: in the nighttime, the atmosphere is stable or lightly unstable and turbulence is the result of mechanical processes, while during the daytime, or free convection regime, the atmosphere is unstable and the turbulence is the result of free convection of thermals of rising hot air, associated with the mechanical processes wind shear. In the nocturnal regime, a first order closure based on $\mathrm{K}$ theory approximation is used to determine the turbulent fluxes. $\mathrm{K}$ theory approximation, also called mixing-length theory, is a method of describing the movement of trace species on the turbulent or subgrid scale; the theory relates the fluxes of the trace species to the gradient of the mean quantities via eddy diffusivity denoted $\mathrm{K}$. Considering the nocturnal regime as a local scheme, the mixture is assumed to occur only between adjacent layers in the model. The free convection regime employs a non-local approximation in which buoyancy plumes of hot air are assumed for the mixing of heat, humidity and momentum for each level in the mixing layer.
The B-T scheme available in MM5 is based on its initial implementation in NORAPS (Burk and Thompson, 1989). The PBL turbulence parameterization scheme with local second order closure is based on level 3 of Mellor and Yamada (1974). In the MM5 model, this scheme is used to predict the vertical mixing of horizontal wind, potential temperature, water vapor mixing ratio, cloud water and rain water through prognostic equations for the turbulent kinetic energy (TKE), temperature, humidity and a covariance of temperature and humidity. All other flows are obtained diagnostically. Their inclusion in the prognostic equations for larger statistical moments permits the simulation of better mixed PBLs, but with a large computational increase. It is a local closure PBL scheme of order 1 and $1 / 2$ with a prognostic equation for turbulent kinetic energy.

The parameterization based on modeling developed by Janjic (1994), which will be called from here only as ETA, uses equations defined by Mellor and Yamada (1974), who consider the closure of second-order turbulence for the TKE and calculate the turbulent fluxes from it. According to Janjic (1994), this model assumes two distinct layers in PBL: a thin viscous layer above the surface, where the vertical transport

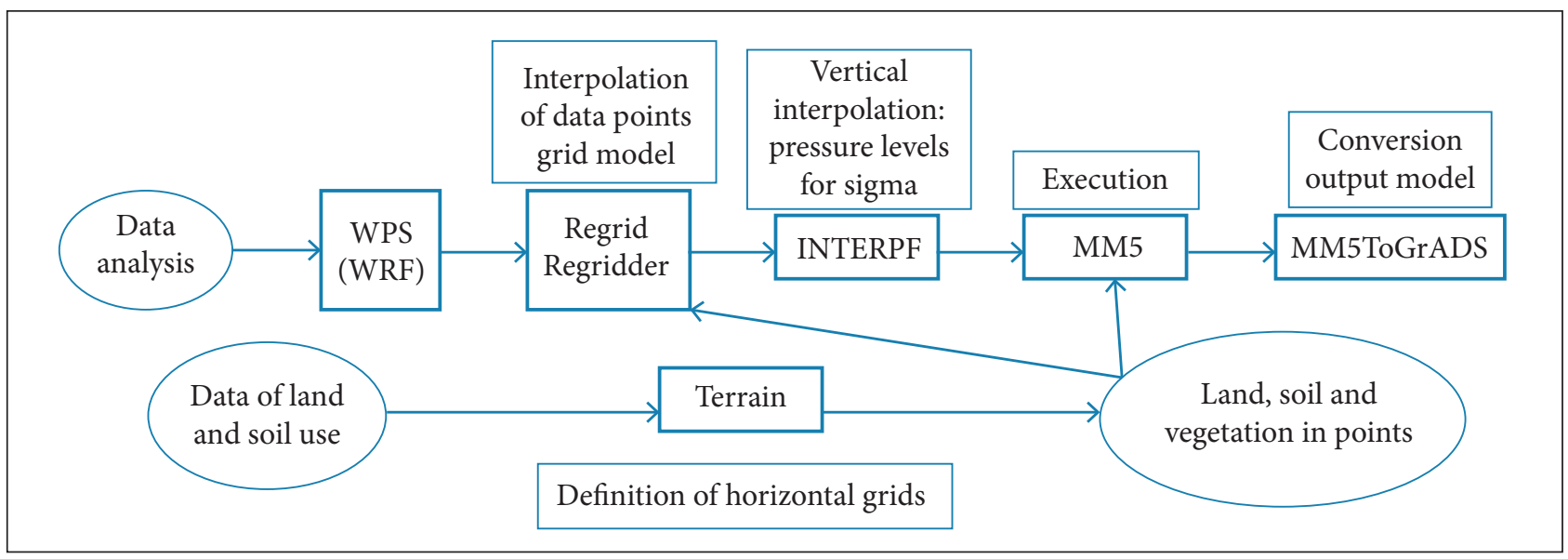

Figure 2. Flowchart of operation of the hybrid mesoscale model MM5.

Table 1. PBL parametrization schemes tested in MM5.

\begin{tabular}{|c|c|c|c|c|c|c|}
\hline Name & Abbreviation & $\begin{array}{c}\text { Original } \\
\text { scheme }\end{array}$ & $\begin{array}{c}\text { Closure } \\
\text { order }\end{array}$ & $\begin{array}{c}\text { Theory for vertical } \\
\text { turbulent diffusion }\end{array}$ & $\begin{array}{c}\text { Vertical } \\
\text { diffusion }\end{array}$ & $\begin{array}{c}\text { Surface layer } \\
\text { similarity }\end{array}$ \\
\hline Blackadar & BLK & Blackadar & First order & K-theory & non-local & Monin-Obhukov \\
\hline Burk-Thompson & B-T & Mellor-Yamada & $\begin{array}{c}\text { Second } \\
\text { order }\end{array}$ & TKE & local & Louis \\
\hline Mellor-Yamada & ETA & Mellor-Yamada & Order 1.5 & TKE & local & Monin-Obhukov \\
\hline Hong-Pan & MRF & Troen-Mahrt & First order & K-theory & non-local & Monin-Obhukov \\
\hline
\end{tabular}

Source: Adapted from Camillo (2011). 
is determined by molecular diffusion, and a turbulent layer, where the vertical transport is dominated by turbulent flows. The thickness of the viscous layer is different relative to the temperature, specific humidity and wind speed and depends on the friction of its molecular diffusivity of each variable (Reynolds number). Additionally, viscous layers for temperature and humidity respectively depend on the Prandtl and the Schmidt numbers. These layers are much thinner than the surface layer. The turbulent flows of the different variables in the surface layer above the viscous layer are equal to those of the viscous layer and function of the gradient of these variables and coefficients of heat exchange and momentum defined by Mellor and Yamada. In MM5, the scheme is used to predict the vertical mixing of horizontal wind, potential temperature and mixing ratio.

An efficient scheme named MRF based on the Troen-Mahrt representation of the contragradient term and non-local $\mathrm{K}$ approximation (Hong and Pan, 1996) is a non-local scheme of first order based on results from large eddy simulations by Wyngaard and Brost (1984). In this scheme, there is a flow parametrization contrary to the gradient, which depends on the convective velocity and the flow to the surface. It has been used in general circulation and numerical weather prediction models due to its computational efficiency. In the MM5 model, the scheme is used to predict the vertical mixing of horizontal wind, potential temperature, water vapor mixing ratio, cloud water and cloud ice.

\section{DESCRIPTION OF THE EXPERIMENTS}

The initial and boundary conditions for the simulations were based on data from the Global Forecast System (GFS) global model. The model integrations were initialized using the 12 UTC analyses and extended for 72 hours. The first 12 hours of the simulation were not evaluated and the results were discarded as spin-up. The zonal ( $\mathrm{u}$ ) and meridional (v) wind components simulated were obtained for the grid point location closest to the CLA, whose coordinates are $2.23039^{\circ} \mathrm{S}$ and $44.4617^{\circ} \mathrm{W}$. These variables are compared with the observations derived from radiosoundings. The wind analysis is done in the lower atmosphere; in this case, from the surface to $700 \mathrm{hPa}$, this is equivalent to a height up to 5,000 meters, because these are the altitudes where there are the largest rocket trajectory corrections.

Also, other additional input data are:

- Frequency of boundary conditions is that established by analysis and forecast files obtained from the National
Centers for Environmental Prediction (NCEP) site. For MM5, files were obtained every 6 hours.

- Atmospheric information to the initial conditions: GFS analysis and forecasts. The program WPS, the WRF system, is used to read files in GFS format GRIB2 because the program responsible for this task only reads the MM5 format GRIB1.

- Sea surface temperature (SST) to the boundary conditions: the issue of SST is one aspect that still remains to be implemented in hybrid MM5. Therefore, the surface temperature was used in place of SST, given that this comes from the GFS file and is processed by the WPS.

- Moisture and soil temperature to the boundary conditions: these conditions were obtained from the GFS file.

The tested configuration of the MM5 can be summarized as: two domains nested; horizontal grid spacing of $18.6 \mathrm{~km}$; number of the points of the domain size - $130 \times 130,121 \times 121$; 26 vertical levels and initialization at 12:00 UTC using GFS data. For the comparison of results, the parameterization MRF PBL was considered as reference or control and three other PBL parameterization options like BLK, ETA and BT were varied.

The physical parameterizations of the model are as follows: cloud radiation scheme for radiation; processes for multilayer surface; Grell for convection implied (Grell, 1993), which considers only a cloud-sized two-dimensional parameterization of vertical downward and upward movements and considers that there is only air mixture saturated with air at the top and the cloud base; simple ice (Dudhia, 1989) for cloud microphysics, which states that processes associated with the ice phase are more important in a layer between $0^{\circ}$ and $-20^{\circ} \mathrm{C}$, where the vertical movements are forced to rise by releasing latent heat that results from deposition of water vapor in the snow.

\section{METRIC FOR THE EVALUATION OF THE MM5 MODEL}

In order to analyze the correlation of the simulation data in relation to the observations, the Willmott coefficient $\boldsymbol{d}_{r}$ (Willmott et al., 2011) was utilized according to Eqs. 1 and 2. It can be calculated as:

If

$\sum_{i=1}^{n}\left|P_{i}-O_{i}\right| \leq c \sum_{i=1}^{n}\left|O_{i}-\bar{O}\right|$

Then 
$d_{r}=1-\frac{\sum_{i=1}^{n}\left|P_{i}-O_{i}\right|}{c \sum_{i=1}^{n}\left|O_{i}-\bar{O}\right|}$

If

$\sum_{i=1}^{n}\left|P_{i}-O_{i}\right|>c \sum_{i=1}^{n}\left|O_{i}-\bar{O}\right|$

Then

$d_{r}=\frac{c \sum_{i=1}^{n}\left|O_{i}-\bar{O}\right|}{\sum_{i=1}^{n}\left|P_{i}-O_{i}\right|}$

where:

$P_{i}$ : estimated value of a variable of order $i$; $O_{i}$ : observed value of a variable of order $i$; $\bar{O}$ : mean of the estimated values of a variable; $n$ : number of events.

The value of $c$ was assumed as 2, according to Willmott et al. (2011).

The interpretation of $d_{r}$ is relatively simple: it indicates the sum of the magnitudes of the differences between the deviations of the model and observed values about the observed mean in relation to the sum of the magnitudes of the perfect model $\left(P_{i}=O_{i}\right.$, for all $i$ ) and the observed deviations about the observed mean. Since the Willmott index can vary in the interval of -1.0 to 1.0, here the evaluation criteria presented in Table 2 were considered.

Table 2. Evaluation criteria adopted by Willmott.

\begin{tabular}{|c|c|}
\hline Interval & Performance \\
\hline 1.0 to 0.75 & Excellent \\
\hline 0.75 to 0.5 & Good \\
\hline 0.5 to 0.25 & Reasonable \\
\hline 0.25 to -0.25 & Fair \\
\hline-0.25 to 0.5 & Unsatisfactory \\
\hline-0.5 to -0.75 & Poor \\
\hline-0.75 to 1.0 & Very poor \\
\hline
\end{tabular}

\section{RESULTS}

In this section, we will try to identify the main differences between the parameterizations of PBL with respect to the ability of the model to predict 60 hours of wind in terms of zonal $(u)$ and meridional $(v)$ components. The first 12 hours are not assessed and they are discarded as spin-up time effect. The two periods were analyzed as dry period of 2008 since 17 September at 12:00 UTC until 21 September at 12:00 UTC and as rainy period of 2010 since 19 March at 12:00 UTC until 25 March at 12:00 UTC.
The evaluation of the simulation is divided into two parts. First, a purely graphical comparison was made between the results obtained from the simulations, so considering each type of CLP parametrization with the observed value and also comparing with the NCEP reanalysis (Figs. 3 to 6). In the second part, the statistical metric Willmott index of agreement was used in the analysis, considering every 12 hours in advance prediction regarding the observation, namely, 60, 48, 36, 24 and 12 hours before the event.

\section{GRAPHIC ANALYSIS}

\section{Year 2008}

Considering for September 17, 2008 a booting from 12:00 UTC (Fig. 3), the ETA simulations (Fig. 3c), BLK (Fig. 3d), BT (Fig. 3e) and MRF (Fig. 3f) tend to overestimate, especially ETA and BT parameterizations, the zonal wind above $925 \mathrm{hPa}$. The startup from 12:00 UTC did not result in better forecasting for the meridional component (Fig. 4). It was noticed a change in the sign of the meridional component from 1,000 to $700 \mathrm{hPa}$, where, in the lower levels, the value

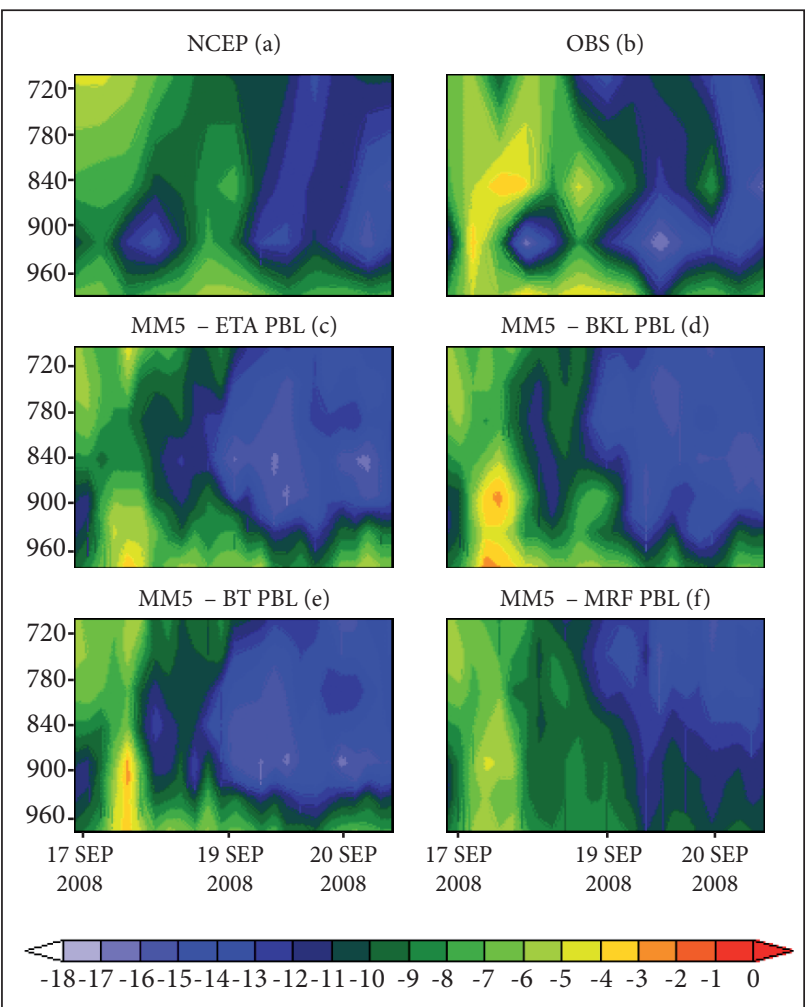

Figure 3. Example of comparisons of the zonal wind component (m/s) between 1,000 and $700 \mathrm{hPa}$. (a) Reanalyses - NCEP;

(b) Radiosoundings at CLA; MM5 simulations utilizing the ETA

(c), BLK (d), BT (e) and MRF (f) parametrizations. 
is negative; from $850 \mathrm{hPa}$, it turned positive (Fig. 4b). Simulations (Figs. 4c, 4d, 4e and 4f) follow this change of sign of the meridional component, but with less fluctuation.

Concerning Figs. 3 and 4 for the zonal wind, simulation results near to $1,000 \mathrm{hPa}$ suggested that ETA, BLK and BT parametrizations had better performance than the reference parameter, in this case, the MRF parametrization. From layer 925 to $700 \mathrm{hPa}$, there was not much difference between all parameterizations, which is best for predictions of 60 and 72 hours. In this case, there was no difference between the boots 00:00 (not shown) and 12:00 UTC. That is, the parameter did not appear to be important, either initialization. Possibly, this result is related to cloud microphysics.

It was found that, for the first levels of the atmosphere, between 1,000 and $925 \mathrm{hPa}$, the meridional component was best predicted by MM5 when it defined the BLK and MRF PBL parameterization as options. The intermediate layer, between 925 and $850 \mathrm{hPa}$, was not well-provided for any of the times, from the parameterization options studied, even by reference parameter, i.e. it may be that the type of PBL parameterization

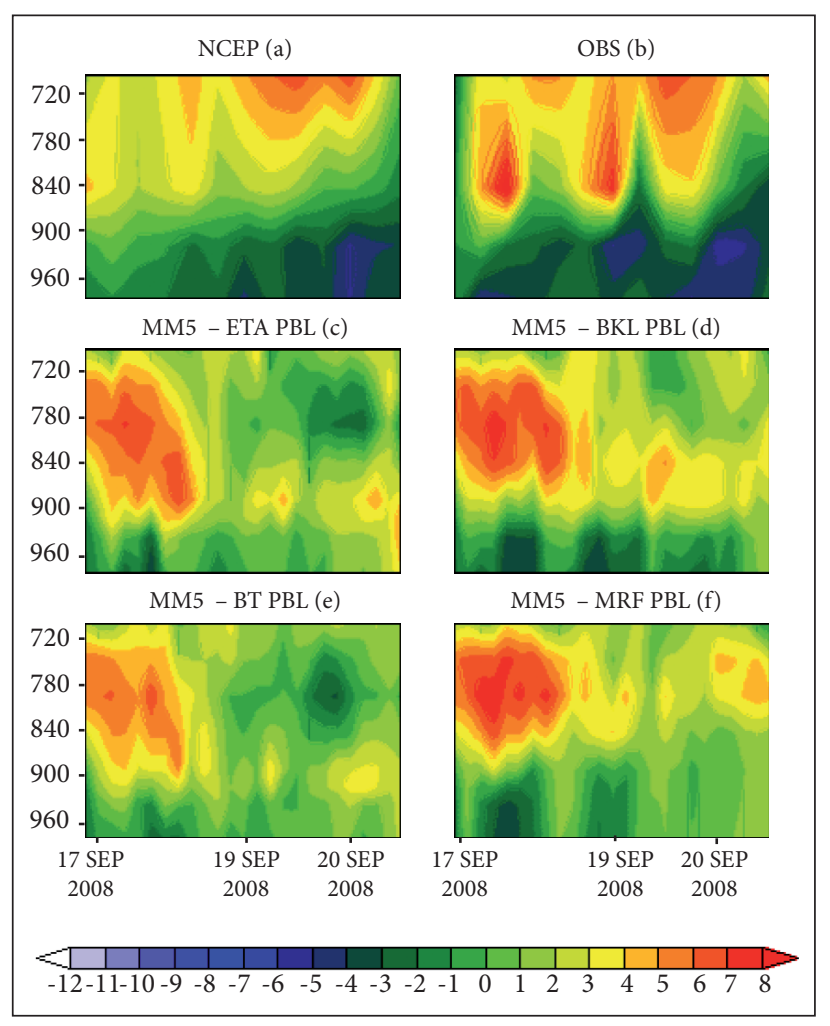

Figure 4. Example of comparisons of the meridional wind component (m/s) between 1,000 and $700 \mathrm{hPa}$. (a) Reanalyses - NCEP. (b) Radiosoundings at CLA; MM5 simulations utilizing the ETA (c), BLK (d), BT (e) and MRF (f) parametrizations. chosen do not interfere in the prediction of this wind component of the atmosphere at these levels. Between 850 and $700 \mathrm{hPa}$, wind component was well-provided forecasts of 24, 36 and 48 hours for all the parameterizations, being the BLK parameterization the foremost among them. For the meridional component of the wind, there was no difference between the boots from 00:00 (not shown) to 12:00 UTC; the boots from 12:00 UTC were closer to the observation, mainly from 1,000 to $925 \mathrm{hPa}$ layer.

\section{Year 2010}

Figures 5 and 6 show the zonal and meridional components provided from the day March 19 at 12:00 UTC until the $22^{\text {th }}$ at 12:00 UTC. ETA (Fig. 5c), BLK (Fig. 5d) and BT (Fig. 5e) simulations and also data from the NCEP reanalysis (Fig. 5a) underestimated the observed zonal. Only the prediction MRF (Fig. 5f) was treated in the observation of the entire length of the air layer and analyzed throughout the forecast.

From radiosonde launches at 12:00 UTC (Fig. 6), it was noted again the permanence of negative sign of the simulated meridional component for all forecasts (Figs. 6c, 6d, 6e and 6f)

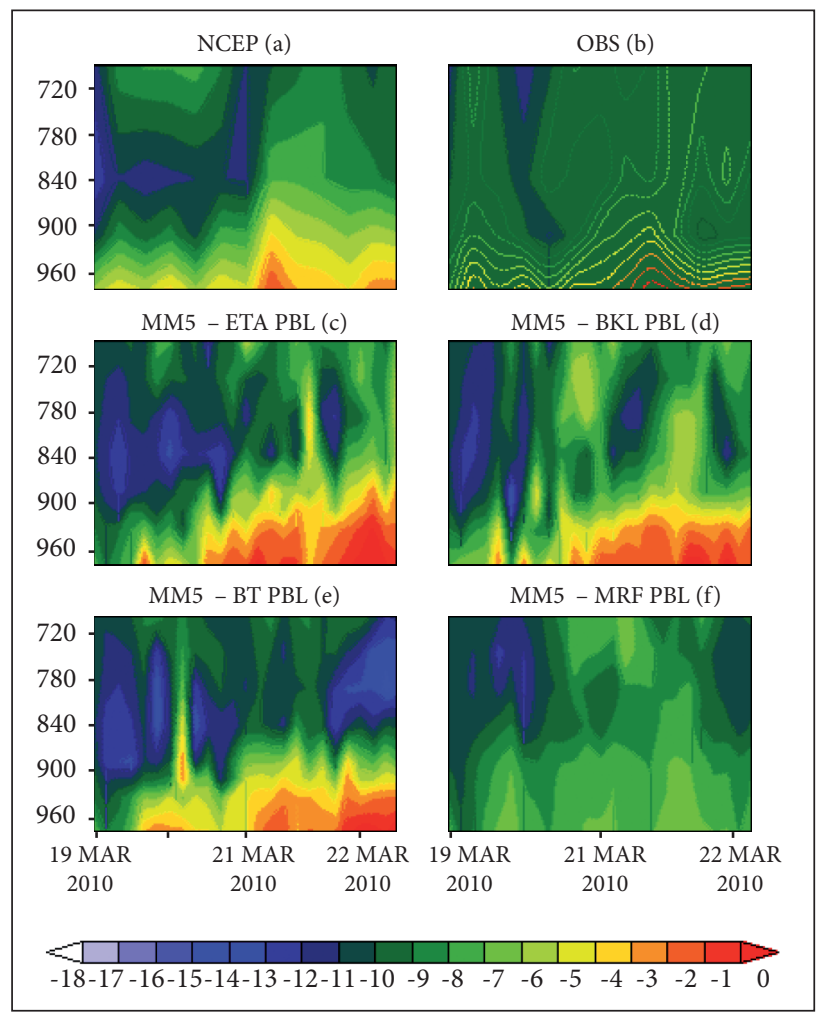

Figure 5. Example of comparisons of the zonal wind component (m/s) between 1,000 and $700 \mathrm{hPa}$. (a) Reanalyses - NCEP. (b) Radiosoundings at CLA; MM5 simulations utilizing the ETA (c), BLK (d), BT (e) and MRF (f) parametrizations. 
above $925 \mathrm{hPa}$, unlike the observed (Fig. 6b). Nevertheless, both are close to the value observed 24 hours after the start of simulation from 1,000 to $850 \mathrm{hPa}$. The MRF (Fig. 6f) simulation was a little closer observation, with only $1-2 \mathrm{~m} / \mathrm{s}$ apart (Fig. 6b).

The graphic result of 2010 simulations showed that when the simulations were initialized at 00:00 UTC (not shown) between levels 1,000 and $925 \mathrm{hPa}$ and between 700 and $850 \mathrm{hPa}$, the MRF parametrization was not surpassed by any other, that is, the prediction of zonal values obtained better results using the MRF; however, at levels between 925 and $850 \mathrm{hPa}$, the ETA, BLK, BT the parametrizations were better than the MRF, although underestimated the observed values. Whereas, when the simulations were initialized at 12:00 UTC, no parametrization was more close to the observation than the MRF parametrization, considering the whole period of 72 hours for any layer of the atmosphere studied.

According to the results obtained for the meridional component, this was not well-simulated by the PBL parameterization when initialized at 00:00 UTC (not shown)

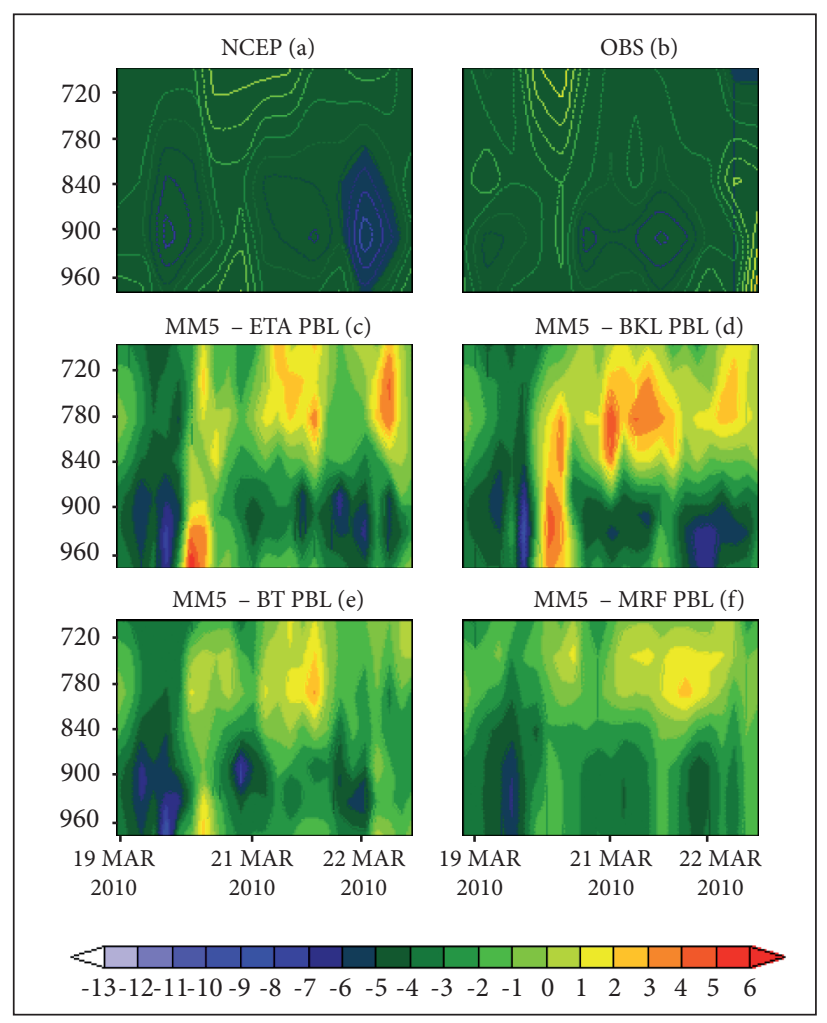

Figure 6. Example of comparisons of the meridional wind component (m/s) between 1,000 and $700 \mathrm{hPa}$. (a) Reanalyses - NCEP. (b) Radiosoundings at CLA; MM5 simulations utilizing the ETA (c), BLK (d), BT (e) and MRF (f) parametrizations. and, when subjected to commence at 12:00 UTC, the ETA, BT and BLK parameterizations approached, but not exceed, the performance of MRF, which was better in 1,000 to $850 \mathrm{hPa}$ layer.

\section{VERTICAL PROFILES}

\section{Vertical Profile for the Dry Season (2008)}

Figure 7 shows the forecasts with 24, 36, 48, 60 and 72 hours in advance of vertical profiles of wind speed and direction for the day September 20, 2008 from simulation initialized on September 17, 2008 at 00:00 UTC. For wind speed, the performance of the model estimates varied schedules. In some cases, the result was better forecasts for 24 and 72 hours of model integration also depending on when the simulation is initiated: 00:00 and 12:00 UTC (not shown).

The wind direction seemed to be better predicted by the model than the speed compared to observation. The parameterizations used predicted values of wind direction very close to the observations, but at certain times of the simulations with the MM5 MRF parameterization set up closer to the real value. As the wind speed, the time (integration time of the model) in which the prediction of wind direction is better was not defined. The rates differ from 1.0 to $5.0 \mathrm{~m} / \mathrm{s}$ approximately, and the worst predictions of wind direction reached on average around 40 degrees of difference relative to the observed.

\section{Vertical Profile for the Rainy Season (2010)}

The vertical profiles of wind speed and direction for March 22 are shown in Fig. 8. In the same way as observed in the dry season (2008), the rainy season was not well-defined times when the predictions are better. The analysis results revealed some differences of up to $5.0 \mathrm{~m} / \mathrm{s}$ of wind intensity between the simulated and the actual value, as in the simulation for March 22, 2010 at 00:00 UTC (Fig. 8), which was wellsimulated by the model considering all parameterizations, almost throughout the integration period. However, for the final time (over 60 hours), this did not happen, mainly for ETA parameterization levels of 925 and $850 \mathrm{hPa}$. It was noted that the simulations from the MRF parameterization stood out among the others also in predicting the speed and the prediction of wind direction. An observed result is that forecasts of 24, 60 and 72 hours were better for the wind direction during the rainy season.

The results indicated the considerable potential of PBL parameterizations to improve the quality of wind forecasts in the short-term generated by MM5. Furthermore, these 
results show that the impact of parameterization is also not felt throughout the length of the atmosphere studied here between the levels of 700 and $1,000 \mathrm{hPa}$, that is, there are limitations in the wind forecast, in terms of $u$ and $v$ components; in parts of this layer, sometimes a particular parameterization performs better near the surface and, at other times, at higher levels. Basically, considering all tested options, it was noted that the model presented errors in wind velocity field mainly in $1,000 \mathrm{hPa}$. This represents that the wind field near the surface did not respond well to main features of CLA relief or suggests that we should adjust not only the parameterization of PBL, but also the physics of clouds parametrization. Considering the entire atmosphere layer studied, between 1,000 and $700 \mathrm{hPa}$, the differences were smaller in the dominant sectors of the wind, in this case, NE and SE, which somehow reduces this limitation since the most important sectors are reasonably simulated by the model.

\section{Analysis of Concordance of Willmott Index}

The impact in defining the parameterization of the MM5 PBL ideal for CLA, obtained by the wind forecast, has been reported for the dry and rainy seasons. The Willmott agreement index signaled some important results in search for the best parameterization of PBL. On average, the best results were Willmott index forecasts for 60 hours in advance, so during the dry period and for the rainy one.

Table 3 presents the comparison of the simulation results obtained for the different PBL parameterizations for the period from September 16, 2008 at 12:00 UTC to September 21, 2008 at 12:00 UTC for the zonal and meridional components. The best result for the Willmott index regarding the zonal component was for the MRF parametrization on both domains with values of -0.07 or fair performance for the 60 -hour forecasts. The best result obtained for the meridional component of the Willmott value was -0.28 or unsatisfactory for BLK on domain 1 and -0.32 or unsatisfactory for MRF on domain 2.

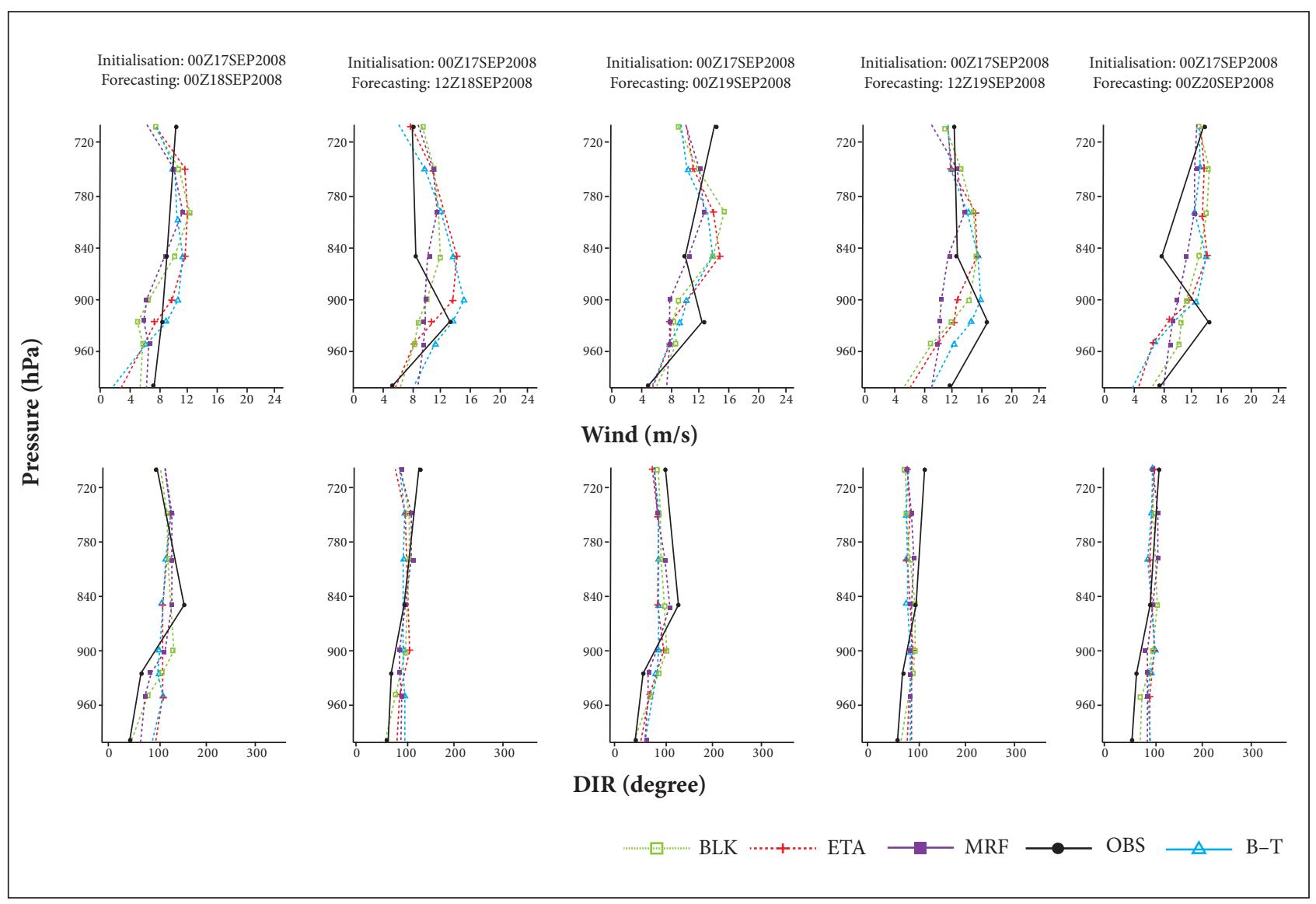

Figure 7. Example of the comparison of vertical wind profiles $(\mathrm{m} / \mathrm{s})$ predicted with the ETA, BLK, BT and MRF parametrizations and the radiosounding observations (OBS) in the layer from 1,000 to $700 \mathrm{hPa}$ for forecast times of 24, 36, 48, 60 and 72 hours. 
Table 4 shows results for the zonal and meridional components from the simulations initialized at 12:00 UTC for the period from March 20, 2010 at 12:00 UTC to March 25, 2010 at 12:00 UTC, in this case, wet season. The MRF parameterization did not obtain a good result; nevertheless, it was still better than the other parameterizations, both on domain 1 , where it was observed the value of 0.17 , as on domain 2, where it was observed the value of 0.14 . That is, for both domains, it was considered fair according to the Willmott index.
Based on the results obtained, it was identified that, on average, the best results for the Willmott index were related to forecasts of 60 hours. In addition, it was perceived that the ETA and BT parametrizations are not adequate for the CLA or for the north coast of NE Brazil. Considering the dry (2008) and wet (2010) seasons, in general, the MRF parameterization, which is considered the MM5 default parametrization, still presented the best results. In addition to this reference parameterization, the BLK was the other that stood out.

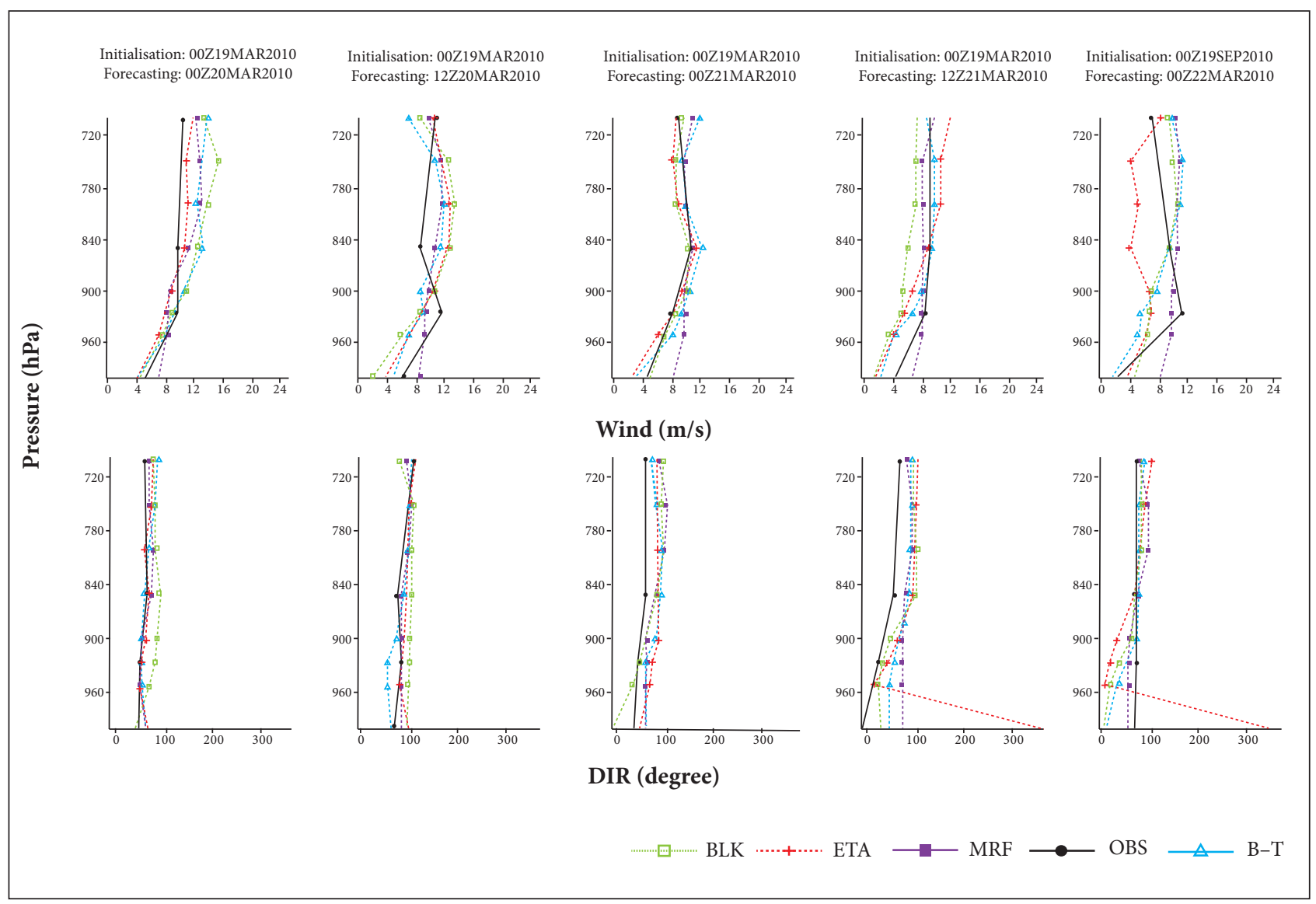

Figure 8. Example of the comparison of vertical wind profiles $(\mathrm{m} / \mathrm{s})$ predicted with the ETA, BLK, BT and MRF parametrizations and the radiosounding observations (OBS) in the layer from 1,000 to $700 \mathrm{hPa}$ for forecast times of 24,36 , 48,60 and 72 hours.

Table 3. Statistical indices obtained for the zonal and meridional components from 1,000 to $700 \mathrm{hPa}$ for the period of the dry season.

\begin{tabular}{|c|c|c|c|c|c|c|c|c|c|c|c|}
\hline \multicolumn{6}{|c|}{ Zonal component - 2008} & \multicolumn{6}{|c|}{ Meridional component - 2008} \\
\hline \multicolumn{6}{|c|}{ Domain 1} & \multicolumn{6}{|c|}{ Domain 1} \\
\hline Statistical index & Forecast & MRF & BLK & ETA & BT & Statistical index & Forecast & MRF & BLK & ETA & BT \\
\hline Willmott & 60 & -0.07 & -0.08 & -0.11 & -0.09 & Willmott & 24 & -0.31 & -0.28 & -0.35 & -0.33 \\
\hline \multicolumn{6}{|c|}{ Domain 2} & \multicolumn{6}{|c|}{ Domain 2} \\
\hline Willmott & 60 & -0.07 & -0.07 & -0.11 & -0.11 & Willmott & 24 & -0.32 & -0.36 & -0.38 & -0.36 \\
\hline
\end{tabular}


Table 4. Statistical indices obtained for the zonal and meridional components for the atmospheric layer from 1,000 to $700 \mathrm{hPa}$ for the period of rainy season.

\begin{tabular}{|c|c|c|c|c|c|c|c|c|c|c|c|}
\hline \multicolumn{6}{|c|}{ Zonal component - 2010} & \multicolumn{6}{|c|}{ Meridional component - 2010} \\
\hline \multicolumn{6}{|c|}{ Domain 1} & \multicolumn{6}{|c|}{ Domain 1} \\
\hline Statistical index & Forecast & MRF & BLK & ETA & BT & Statistical index & Forecast & MRF & BLK & ETA & BT \\
\hline Willmott & 60 & 0.17 & 0.14 & 0.07 & 0.12 & Willmott & 60 & 0.28 & 0.22 & 0.19 & 0.24 \\
\hline \multicolumn{6}{|c|}{ Domain 2} & \multicolumn{6}{|c|}{ Domain 2} \\
\hline Willmott & 60 & 0.14 & 0.10 & 0.02 & 0.06 & Willmott & 60 & 0.29 & 0.22 & 0.16 & 0.22 \\
\hline
\end{tabular}

\section{CONCLUSION}

It was noticed in this experiment that ETA and BT parameterizations are not suitable for the CLA. Considering the available data set, in general, both default MRF and BLK parameterization presented suitable schemes. The former is better for the wet season and the latter gave the best results for the dry season. An important factor that must be emphasized is that both parameterization schemes are non-local schemes. In this case, the non-local scheme is related to vertical diffusion, which is an important process that considers the effects of eddies moving to larger distances according to the physical processes that occur in turbulent atmosphere. The larger eddies are more important as they are more sensitive to the environment. This can be the cause of the MM5 model subtly better predict the wind in PBL considering these schemes, given that non-local schemes better simulate the deep and large eddies PBLs.

It was also found that the initializations at 12:00 UTC are better than those at 00:00 UTC. Elleman et al. (2003) assert that many of the parameterizations of the boundary layer MM5, including the MRF, tend to promote an excessive vertical mixing, which means that the errors they produce are higher during the night, that is, when there is the smallest vertical mixing. Possibly overnight, the main process responsible for errors generated is the cloudiness provided, which controls the radiation of long radiation lost to space.

\section{REFERENCES}

Blackadar, A.K., 1976, "Modeling the Nocturnal Boundary Layer". Proceedings of the 3rd Symposium on Atmospheric Turbulence, Diffusion and Air Quality, Boston, USA.

Burk, S.D. and Thompson, W.T., 1989, "A Vertically Nested Regional Numerical Weather Prediction Model with Second-Order Closure Physics", Monthly Weather Review, Vol. 117, pp. 2305-2324.

Camillo, G.L., 2011, "Impacto das Parametrizações de Camada Limite Planetária do MM5 na Previsão de Ventos em Baixos Niveis", Revista da Universidade da Força Aérea, Vol. 23, No. 28, pp. 67-79.

Carvalho, M.A.V., 2011, "Variabilidade da Largura e Intensidade da Zona de Convergência Intertropical Atlântica: Aspectos Observacionais e de Modelagem", Master's Dissertation, Instituto Nacional de Pesquisas Espaciais, São José dos Campos, Brazil.

Dudhia, J., 1989, "Numerical Study of Convection Observed during the Winter Monsoon Experiment Using a Mesoscale TwoDimensional Model", Journal of Atmospheric Sciences, Vol. 46, No. 20, pp. 3077-3107. doi: 10.1175/1520-0469(1989)046<3077: NSOCOD>2.0.CO;2

Dudhia, J., Gill, D., Guo, Y., Manning, K., Wang, W., and Chiszar, J., 2003, "Mesoscale Modeling System Tutorial Class Notes and User's Guide: MM5 Modeling System Version 3”, PSU/NCAR.

Elleman, R.A., Covert, D.S. and Mass, C.F., 2003, "Comparison of ACM and MRF Boundary Layer Parameterizations in MM5", Proceedings of the Models-3 Workshop, Raleigh, USA.
Grell,G.A., 1993, "PrognosticEvaluation ofAssumptionsUsedbyCumulus Parameterizations", Monthly Weather Review, Vol. 121, pp. 764-787. doi: 10.1175/1520-0493(1993)121<0764:PEOAUB>2.0.CO;2

Grell, G.A., Dudhia, J., and Stauffer, D.R., 1994, "A Description of the Fifth-Generation Penn State/NCAR Mesoscale Model (MM5)", NCAR Technical Note, NCAR/TN-398+STR, Boulder, USA, 117 p.

Hong, S.-Y. and Pan, H.-L., 1996, "Nonlocal Boundary Layer Vertical Diffusion in a Medium-Range Forecast Model", Monthly Weather Review, Vol. 124, No. 10, pp. 2322-2339. doi: 10.1175/1520-0493(1996)124<2322:NBLVDI>2.0.CO;2

Janjic, Z., 1994, "The Step-Mountain Eta Coordinate Model: Further DevelopmentsoftheConvection, ViscousSublayer, andTurbulenceClosure Schemes", Monthly Weather Review, Vol. 122, No. 5, pp. 927-945. doi: 10.1175/1520-0493(1994)122<0927:TSMECM>2.0.C0;2

Johnson, D.L., 2008, "Terrestrial Environment (Climatic) Criteria Guidelines for Use in Aerospace Vehicle Development, 2008 Revision", NASA/TM 2008-215633, Marshall Space Flight Center, Alabama, USA.

Mellor, G.L. and Yamada, T., 1974, "A Hierarchy of Turbulence Closure Models for Planetary Boundary Layers", Journal of Atmospheric Sciences, Vol. 31, No. 7, pp. 1791-1806.

Oyama, M.D., 2004, "Precipitação do Modelo de Mesoescala MM5: Avaliação Preliminar da Sensibilidade às Parametrizações de Convecção Profunda em Grade Reduzida", Proceedings of the XIII Brazilian Congress of Meteorology, Fortaleza, Brazil. 
Oyama, M.D. and Giarolla, E., 2006, "Simulação de Linhas de Instabilidade na Costa Norte do Brasil de 6 a 9 de Julho de 2005 com o Uso do Modelo Regional MM5: Resultados Preliminares", Proceedings of the XIV Brazilian Congress of Meteorology, Florianópolis, Brazil.

Pereira Neto, A.V. and Oyama, M.D., 2011, "Mudanças do Esquema de Convecção Profunda Kain-Fritsch para a Região do Centro de Lançamento de Alcântara", Revista Brasileira de Meteorologia, Vol. 26, p. 579-590.

Willmott, C.J., Robeson, S.M. and Matsuura, K., 2011, "A Refined Index of Model Performance", International Journal of Climatology,
Vol. 32, No. 13, pp. 2088-2094. doi: 10.1002/joc.2419

Wyngaard, J.C. and Brost, R.A., 1984, "Top-Down and BottomUp Diffusion of a Scalar in the Convective Boundary Layer", Journal of Atmospheric Sciences, Vol. 41, p. 102-112. doi: 10.1175/1520-0469(1984)041<0102:TDABUD>2.0.CO;2

Zhang, D. andAnthes, R. A., 1982, "AHigh-ResolutionModelofthePlanetary Boundary Layer Sensitivity Tests and Comparisons with SESAME-79 data”, Journal of Applied Meteorology, Vol. 21, No. 11, , pp. 1594-1609. doi: 10.1175/1520-0450(1982)021<1594:AHRMOT>2.0.C0;2 